\title{
Regulator Non-coding RNAs: miRNA, siRNA, piRNA, IncRNA, circRNA
}

\author{
Ertan Altayli \\ Department of Medical Biology, Gülhane Faculty of Medicine, Health Sciences University, Ankara, Turkey
}

Received: 2020-07-29.

Accepted: 2020-09-06

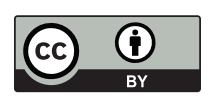

This work is licensed under a Creative Commons Attribution 4.0 International License

J Clin Med Kaz 2020; 6(60):29-39

Corresponding author:

Ertan Altayli.

E-mail: altaylie@gmail.com; ORCID:

\begin{abstract}
Gene expression and its regulation play a central role in maintaining life and generation in all living things. According to the central dogma of genetics, DNA plays a central role in gene expression, RNA is synthesized from DNA, and protein is synthesized from RNA. According to recent research results, human DNA produces more regulator non-coding RNA than protein coding RNAs. These RNAs act as important functional regulatory molecules in various cellular processes, including chromatin remodeling, transcription, post-transcriptional modifications and signal transfer. Therefore, the regulator ncRNAs act as key regulators of physiological programs in terms of development and disease. In this review, the main structural and functional properties of miRNA, SiRNA, piRNA, IncRNA and circRNA defined as regulator ncRNAs are reviewed.

Key words: miRNA, siRNA, piRNA, InCRNA, circRNA
\end{abstract}

\section{Introduction}

In 1838 , cell theory was introduced by Schleiden and Schwann. Microscope examination of plant tissues by Schleiden and animal tissues by Schwann led to the same result: all living things are made up of cells $[1,2]$. Gene expression plays a central role in the maintenance of life and generation in all living beings, whether singlecelled or multi-celled organisms, and the development of all cells and tissues and the provision of homeostasis are possible through regulation of gene expression. DNA plays a central role in gene expression, and RNA is synthesized from DNA according to the dogma expressed centrally in genetics, and protein is synthesized from RNA [3].

Housekeeping RNAs are RNAs that are structurally expressed in gene expression and are essential for normal cellular functions. In carrying out these structural functions in the cell, both encoding (protein coding) RNAs (mRNA) and non-coding (protein non-coding) RNAs (snRNA, tRNA, rRNA, snoRNA) are produced. Messenger RNAs (mRNA) act as a template for protein synthesis, ribosomal RNAs (rRNA) and transfer RNAs (tRNA) are involved in the translation of mRNA into protein. snRNAs (small nuclear RNAs) play a role in splicing to create mature mRNA. snoRNAs (small nucleolar RNAs) have several different types but mainly play a role in the modification of rRNAs [4].

The introduction of regulator non-coding RNAs (ncRNAs) as a different group after 1980s, apart from the above-mentioned RNAs, which played a role in the fulfillment of basic cellular functions, completely changed our thinking about ncRNAs. In studies conducted in E. coli, it was revealed that the first time the micF RNA was discovered, the transcription was regulated by the regulator ncRNAs called micro RNAs (miRNAs) [5]. Following this, lin-4, the first regulator miRNA discovered in C. elegans in the $1990 \mathrm{~s}$, was introduced [6]. In the same years, H19 lncRNA [7], which is a long non-coding RNA (lncRNA) that plays a role in genomic imprint, and Xist lncRNA, which plays a role in X chromosome inactivation, were identified in studies in mice [8]. It was found that miRNAs identified in C. elegans in 1998 regulated the transcription of complementary mRNAs through a mechanism called RNA interference [9]. It was revealed that let-7, the second miRNA identified in C. Elegans in 2000, contains common sequences in human and increases exponentially in human cell lines [10, 11]. In 2002, the first human miRNA was identified in cases of B cell chronic lymphocytic leukemia: miR-15a and miR16-1 [12]. Then the miR17-92 cluster and miR-155 were 
discovered as the first human oncogenic miRNAs $[13,14]$.

While these developments related to the regulator ncRNAs occurred, the first draft results of the Human Genome Project were published in 2001. Later, its deficiencies were completed and the correctly edited results were published in 2004 by the International Human Genome Sequencing Consortium [15]. However, this contradicted the "efficiency principle", which is one of the most fundamental principles of biological systems in terms of "efficiency of the genome", given that proteins represent the primary functional end product of genetic information.

With the ENCODE (Encyclopedia of DNA Elements) project that started in 2003, it was aimed to define all functional elements in the human genome. How much of our genome has "junk DNA" that has no role, and how many of them have a function other than protein coding? The results of the ENCODE project showed that $75 \%$ of the human genome is transcribed and this led to the recognition of the role of non-coding RNAs in the regulation of gene expression. With the ENCODE project, more than 50,000 lncRNAs and as many as 9000 small ncRNAs have been identified [16].

Studies in recent years have shown that there are thousands of unique ncRNA sequences in our tissues and cells. This turned our ncRNA perception from "jung" transcriptional products into functional regulator molecules that mediate cellular processes, including chromatin remodeling, transcription, posttranscriptional modifications, and signal transfer. Networks involving regulator ncRNAs can affect a large number of molecular targets to activate specific cell biology responses and cell destiny. As a result, regulator ncRNAs function as key regulators of physiological programs in terms of development and disease [17].

In this study, the major structural and functional properties of miRNA, siRNA (small interfering RNA), piRNA (RNA interacting with piwi proteins), lncRNA and circRNA (circular RNA), which are defined as regulator ncRNAs, are reviewed.

\section{MiRNA}

miRNA is a transcript of approximately 22 nucleotides in length, which interacts directly with the partially complementary target region located in the 3 'UTR region of the target mRNA (18). This definition was first used by three different research groups working on C. Elegans in 2001 [19, 20]. When the miRNA research area began to expand, experts came together to issue guidelines on how to name these transcripts between species, and a recording system was created so that the same symbols were not used by different research groups for different miRNAs [21, 22]. This miRNA recording system, which was created first, was later transformed into miRBase, the unique and online database system for miRNAs [23].

miRNA maturation is a multi-stage process that begins in the nucleus and ends in the cytoplasm. miRNAs are transcribed by RNA pol II as mono or polysistronic primary miRNA precursors (pri-miRNA). pri-miRNAs contain a $7 \mathrm{mG}$ cap at the 5 'end and a poly A tail at the 3 ' end [24, 25]. Two biosynthetic pathways have been defined for miRNAs. Accordingly, the first pathway is the typical Drosha-dicer dependent biosynthesis pathway. The source of longer pri-miRNAs in this pathway is usually intergenic regions [26]. The second pathway is atypical pathway. The origin of these miRNAs is called mirtrons because they are introns of protein-coding genes [27].

The main mechanism for the typical pathway of miRNA biogenesis in mammals is shown in Figure 1. In a typical pathway, mammalian miRNA is transcribed by RNA

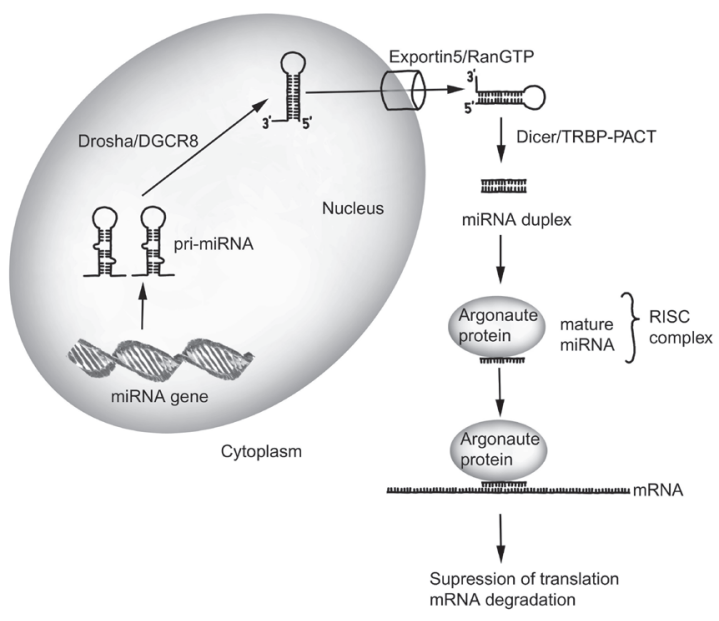

Figure 1. Biosynthesis and mechanism of action of miRNA (Abbreviations: DGCR8: DiGeorge Syndrome Critical Region Gene 8, pri-miRNA: primary miRNA, TRBP: Transactivation Response Element RNA-Binding Protein, RISC: RNA-Induced Silencing Complex).

polymerase II as a primary miRNA (pri-miRNA) transcript. The secondary structure of pri-miRNA formed by base matching can be polyadenylated and regulated by transcription factors [28]. pri-miRNA is detected in the nucleus by the Drosha/ DGCR8 DiGeorge Syndrome Critical Region Gene 8 enzymatic complex. The Drosha enzyme contained in this complex is an RNase III group endonuclease capable of cutting double chain RNA and complexes with DGCR8, a double chain RNA binding protein that acts as a ruler to measure the breakpoint of pri-miRNA. This complex breaks pri-miRNA into a $65-70$ nucleotide precursor RNA (pre-RNA) [29]. The pre-miRNA is folded locally to become a stable hairpin structure, and at the 3 'end of this structure there is a 2 nucleotide protrusion. This feature of the molecule provides specificity for the transport of the exporter 5 to the cytoplasm and its processing by the RNase III dicer enzyme [30]. miRNA is transported to the cytoplasm through the nuclear envelope through the exportin-5 receptor / ran-GTP-dependent mechanism [31]. In eukaryotes, exportin-5 and ran-GTP are similar carrier molecules, and binding of premiRNA to these molecules prevents nuclear degradation of premiRNA and facilitates its transition to cytoplasm [32]. The premiRNA from the cytoplasm is processed into a 22 nucleotide long dsRNA by an "RNase III dicer/double chain RNA binding protein complex". This double-chain RNA-binding protein complex in mammalian cells consists of two proteins. The first of these is "transactivation response element RNA-binding protein (TRBP)" and the second is "protein activator of the interferon-induced protein kinase (PACT)" [33]. In the next step, mature miRNA duplexes bind to the argonate (ago-1-4) protein and "RNA-induced silencing complex (RISC)" is created. In mammal, ago 2 is the main protein associated with mRNA degradation or translation suppression in the RISC complex. Also, single-stranded mature miRNA is also associated with RISC, and this shows sequence matching with the target mRNA. As a result, the RISC complex binds to 3 'UTR regions of the target mRNA and induces post-transcription silencing [34]. The ago-miRNP complex also provides binding of other proteins that mediate the degradation of mRNA or suppression of translation. The main component of mature miRNA for target recognition is the 2-7 nucleotide-long Watson-Crick matching region [35].

Atypical pathway is Drosha independent and dicer dependent pathway. Namely, mirtrons are directly transferred 
to the cytoplasm without being treated with Drosha/DGCR8. Then, mirtrons complete the dicer-dependent processing steps in the cytoplasm, similar to the typical pathway of miRNAs [36]. Some miRNAs are encoded by a gene set such as miR-17 $\sim 92$ gene cluster. In a study with this gene cluster, an intermediate formation called progenitor-miRNA (pro-miRNA) was shown during the processing of the pri-miR-17 $\sim 92 \mathrm{a}$ transcript containing all six miRNAs from this cluster [37].

miRNAs are often transcribed from two target genomic loci. The first is from the miRNA genes in the intergenic region, and the second from the introns of protein-encoding genes [38, 39 ]. It has been demonstrated that there are many miRNA genes in the intergenic regions of chromosomes 1, 14, 19, and X [40]. Many miRNA genes are evolutionarily conserved and most of them interact with mRNAs, indicating their important biological functions [41].

In addition to mRNAs, miRNAs are regulators for non-coding RNAs, such as lncRNAs and circRNAs. It has been shown that miRNA can target several hundred mRNAs, suggesting a complex and combined form of miRNA movement in mRNA regulation [42]. It is estimated that more than $60 \%$ of all mRNAs contain the miRNA target sequence in the 3 'UTR regions [43]. This shows that miRNAs play a role in normal cellular homeostasis and disease states [44]. An increasing number of studies in recent years have revealed that miRNAs play a role in the development of many diseases [45]. These include heart diseases such as hypertrophy and ischemia [46], schizophrenia and major depression [47], deafness [48], stroke [49], psoriasis [50], cirrhosis [51], rheumatoid arthritis [52] and cancer [53].

miRNAs are found in both intracellular and extracellular media and in almost all biological fluids [54]. MiRNAs distributed within exosomes affect inflammation and autoimmunity [55]. Exosomes are cell-derived vesicles containing functional molecules such as RNA, DNA, protein and lipids [56]. Exosomes often mediate intercellular communication by giving functional molecules from donors to recipient cells, including miRNAs, lncRNAs, and circRNAs. Exosomes carrying miRNA have been identified as potential biomarkers for rheumatoid arthritis [57].

The natural structure of miRNAs has a strong potential that can disrupt a large number of cell signaling pathways in the event of abnormal expression, thereby having a profound effect on cancer iniciacion and progression. In numerous articles since the first evidence of miRNAs' role in cancer has been published, miRNAs have been shown to play a role in all stages such as cancer development, progression, metastasis and drug resistance $[58,59]$. In addition, it has been demonstrated that miRNAs can distinguish between normal tissue and cancer tissue and between subtypes of a particular cancer [60]. Therefore, miRNAs can play a key role in drug resistance and as a biomarker for early diagnosis. As a result, the modus operantis obtained so far about miRNAs may play a role in researchers designing artificial miRNAs that target many genes.

\section{SIRNA}

siRNA is produced from a 70-80 bp long double chain RNA (dsRNA) molecule that results from virus replication exogenously and endogenously transposon activity or gene transcription. These double chain RNAs are broken down into 19-24 nucleotide fragments by the RNase III enzyme dicer. These RNA fragments then combine with argonate proteins, causing degradation of the target mRNA [61]. In this mechanism, the breaker endonuclease activity of argonate proteins breaks down target transcripts to perform gene silencing. In this respect, the biosynthesis and mechanism of action of siRNA are similar to miRNA. In addition, some other proteins are involved in translation suppression and specific chromatin modification processes [62]. In the case of endogenous siRNA (endo-siRNA), dsRNA results from elongated hairpin structures or base matching of "sens-antisense" transcripts. Sens-antisense transcripts matching may depend on bidirectional transcription or complementary transcripts of different loci [63]. Endo-siRNAs play a role in silencing transposable elements in mammals. The piRNA pathway serves as an important defense mechanism against repetitive transposable elements in mammalian testicles, while the female germline transposable elements lead to dsRNAs that can be processed into endo-siRNAs. Thus, endosiRNAs contribute to maintaining genomic stability in the female germline [64].

Exogenous siRNAs (exo-siRNA) consist of dsRNAs taken from outside the cell. This mechanism plays a role as an antiviral defense mechanism in nematodes, plants and Drosophila. Here, after the onset of viral infection, viral dsRNAs are processed into siRNAs that target viral mRNAs from which they originate [65]. In addition, a protein-mediated interferon response system for antiviral defense is activated during infiltration of viral long dsRNAs in many differentiated cells [66].

In addition, recent studies have shown that siRNAs can cause transcriptional gene silencing through DNA methylation and histone modification [67]. In a study on this issue, siRNAs were shown to prevent cisplatin resistance in human non-smallcell lung carcinoma (NSCLC) and stomach cancer cells by silencing a histone methyltransferase (EZH2: Enhancer of Zeste Homology-2) [68]. These and similar research results show us that RNA interference pathways may also have regulatory roles on epigenetic mechanisms. In-depth investigation of the siRNAs involved in this process can help us understand the regulation of epigenetic mechanisms accurately.

\section{PIRNA}

piRNA is a 24-31 nucleotide long single chain RNA molecule processed from a single chain precursor RNA transcript [69]. The precursor piRNA is transcribed as a long transcript by RNA pol II. This is then transferred to the cytoplasm and processed independently of the dicer enzyme. The precursor piRNA is processed into mature piRNA by a protein complex that is still not fully known, except for argonate proteins. The piRNA sequences are much more diverse than any known cellular RNA class due to the variety of processing mechanisms and source transposons and constitute the largest non-coding RNA class $[70,71]$. The piRNAs were discovered in the mouse testicles in 2006 by four independent groups. piRNAs play a role in silencing retrotransposons at both post-transcription and epigenetic levels and especially during spermatogenesis [7275]. Transposon regulation by piRNAs is conceptually similar to the immune system that can recognize "self" and "non-self". It is understood that piRNAs use a complex mechanism to select and regulate genes that are not self-contained [76].

Two mechanisms have been characterized in Drosophila, although it is not entirely clear how precursor piRNAs are processed into mature piRNAs. These are primary pathway and secondary pathway (ping-pong cycle) (Figure 2). Members of the argonate protein family [piwi ("P-element-Induced WImpy testis), aub (Aubergine), ago3 (Argonaute)] play an important role from the primary pathway and ping-pong pathway. In the primary pathway, piRNAs are expressed and processed from 


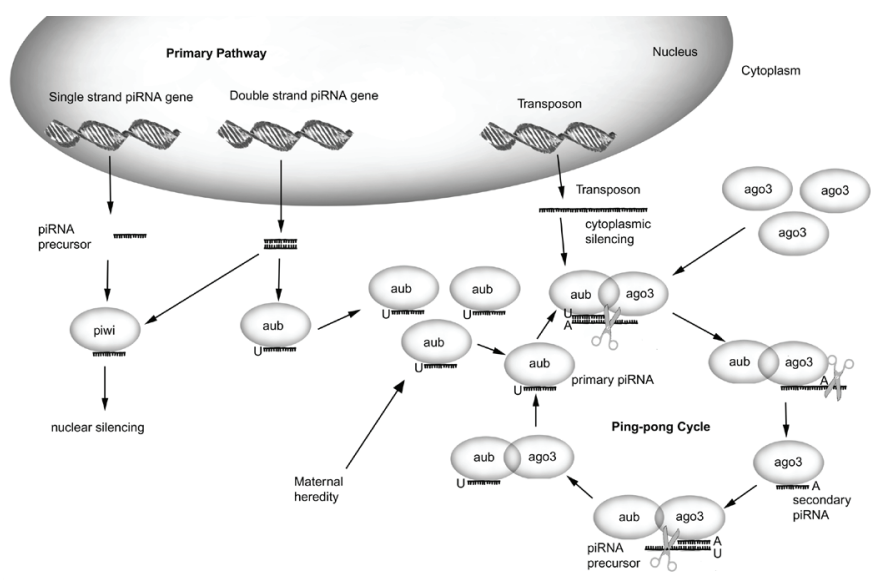

Figure 2. piRNA biogenesis pathways (Abbreviations: Aubergine: aub, Argonaute: ago, Adenine: A, Uridine: U) [77].

genomic regions called piRNA clusters. The single-stranded piRNA cluster combines with piwi and the double-stranded piRNA cluster with aub to form the piRNA-induced silencing complex (piRISC). The 3'-UTR sequences of some proteincoding genes can also function as sources of primary piRNAs. The gene silencing function performed by piRISC occurs both in the cytoplasm and in the nucleus. Piwi plays a role in the transcriptional gene silencing process in the nucleus. The ping-pong path is triggered by the aub-piRNA complex along with ago3. The ping-pong path silences the target transposon sequence and also amplifies the piRNA sequence. Some aubpiRNA complexes are transmitted by maternal inheritance [77]. While primary piRNAs tend to contain uridine (U) at their 5 'end (1U trend), secondary piRNAs are complementary to the last 10 nucleotides at the 5 ' ends of primary piRNAs, and therefore tend to be adenine to the tenth nucleotide uridine of secondary piRNAs. (10A trend) [78].

Although the molecular mechanisms of piRNA biogenesis and function have been studied in the last few years, there are some gaps that need to be addressed for mature piRNA production and clarification of cellular functions [79]. However, since the piRNA sequences and piwi proteins differ among species, it is difficult to fully reveal the biogenesis and functions of piRNA [80].

The prototype of piwi proteins is encoded by the drozophila piwi gene, which was originally defined as a basic gene for germ line development [81]. Drozofila has three different piwi genes (ago3, aub and piwi). Of these, piwi and aub play a role in both male and female fertility, but ago 3 is required for female fertility [82]. In addition, Drosophila piRNA pathway regulates transposon activity to protect telomeres [83].

Mice also express three different piwi proteins (MIWI, MIWI2 and MILI). All three PIWI proteins are expressed at different stages during spermatogenesis, but only MILI is expressed in female germ cells, albeit weak. Mutations in mouse PIWI genes affect the male germ line, but not the female germ line [84]. According to the researches, piRNAs in mice are divided into two subgroups. The first is the "pachytene piRNA" group, which mainly occurs during meiosis and continues to be expressed in haploid spermatitis. The other is the pre-pachytenepiRNA group that appears primarily in pre-meiosis germ cells. Although pre-pachytene-piRNAs have the molecular properties of the pachytene piRNA cluster, pre-pachytene piRNAs come from a completely different cluster and contain repetitive sequences [85].
Contrary to conventional gene-silencing mechanisms mediated by other small RNAs, piRNAs were found to have the ability to promote euchromatin histone modifications in Drosophila [86]. Also, a current genome-wide study showed that piRNAs and piwi are strongly associated with chromatin regulation. In this study, piRNAs were shown to suppress HP1a (heterochromatin protein 1a) protein to specific genomic loci, suppressing transcription by RNA pol II by an epigenetic mechanism [87].

Studies have shown that the DNA methyltransferase family (DNMT3a, DNMT3b and DNMT3L) play an important role in transposon methylation. Therefore, the catalytic activities of DNMT3a and DNMT3b are very important in germ cells and somatic cells. DNMT3L is an important regulator of methylation in germ cells [88]. Experiments show that two piwi proteins (MILI and MIWI2) are required to silence LINE-1 and IAP transposons in the testicle, and the deletion of MILI or MIWI2 reduces the level of transposon methylation. MIWI2 is always in the nucleus during the critical methylation time. Small RNA sequence analysis showed that both MILI and MIWI have an upward-acting role in DNMT3L, and then they have an impact on DNMT3a and DNMT3b. These experimental results confirmed that the piwi protein/piRNA complex can mediate the methylation of transposons and that piRNA is a specific determinant of DNA methylation in germ cells [89].

Although the biogenesis and functions of piRNAs are still not fully clear, many studies have managed to compare different expression profiles of these small non-coding RNAs in different tissues, thanks to deep sequencing technology. In a study, researchers specifically aimed to compare the expression differences of sncRNAs in normal tissues and tumor tissues. So they tried to analyze their effects on metastatic disease and their presence in peripheral blood. In NSCLC, piR-L-163 was found to be down-regulated in this cancer cell line compared to the epithelial cell line [90]. In the breast, piR-34736, piR-34249, piR-35407, piR-36318, piR-34377, piR-36743, piR-36026 and piR-31106 were significantly differentiated between tumor and matched non-malignant tissue [91].

Recent studies have uncovered numerous cytoplasmic factors that play a role in piRNA biogenesis, as well as some nuclear factors that recognize and copy piRNA clusters to produce piRNA precursors or function in piRNA-mediated transcriptional silencing. In addition, some studies on eukaryotes have identified piRNAs that target protein-encoding genes and piRNAs that transmit transposon activity over generations [92].

\section{IncRNA}

RNAs that are longer than 200 nucleotides and have no protein coding potential are called lncRNAs. All mammalian lncRNAs have few common structural, functional or mechanical properties. Only some of the estimated thousands of mammalian lncRNAs have been mechanically characterized to date, and fewer have been functionally validated in vivo. LncRNAs vary widely in their properties, localization and mode of action [93, 94]. A small number of IncRNAs were identified before the human genome was sequenced; H19, BCYRN1 (BC200) and XIST [95-97]. However, the existence of a large number of transcripts, which appeared to be untranslated after the disclosure of the human genome sequence in 2001, emerged [98]. These were originally called mRNA-like ncRNAs; because they are usually transcribed by RNA pol II and caping, splicing, and polyadenylated, like protein-encoding mRNAs [99]. After many studies on non-coding transcripts in humans and mice, the term 
"long" was first used in 2007 to refer to transcripts containing more than 200 nucleotides [100]. Although it was later revealed that some of the lncRNAs have coding potential, the term "IncRNA" has become a useful shorthand and has taken its place in the scientific literature. Since lncRNAs have secondary and tertiary structures, they display RNA and protein-like functions [101]. LncRNAs produce various effects depending on RNA-protein, RNA-DNA and RNA-RNA interactions, and their cytocymetry and localization in a particular cellular compartment. lncRNAs are mainly transcribed by RNA pol II and III in human, but are also produced by pol $\mathrm{V}$ in other eukaryotic organisms [102].

lncRNAs can occur due to different reasons: (1) it can be caused by the disruption of the translational reading frame of a protein encoding gene, (2) it may be caused by chromosomal reorganizations, (3) it can be produced by replication of a non-coding gene by retrotransposition, (4) can be created by duplication of tandem sequences, (5) may result from insertion of a transposable element [103].

In general, lncRNAs are classified according to the regions from which they originate from the genome and their positions within the genome. Accordingly: (1) Intronic lncRNAs: All are within the intron of a protein encoding gene and consist of intronic transcripts. Few of the classified lncRNA genes make up this group. (2) Intergenic lncRNAs: An lncRNA gene is considered intergenic if it does not coincide with a protein coding gene in both strands, does not share a bidirectional promoter with a protein coding gene, and is not a host gene for a miRNA. (3) Sens lncRNAs: These are lncRNAs obtained from transcripts that overlap with a protein encoding gene on the same strand. This category should be applied carefully because it has been shown that such IncRNA genes can then be combined with the protein coding locus. (4) Antisense lncRNAs: If an lncRNA gene coincides with a protein-encoding gene on the opposite strand, it is considered an antisense and no exon-exon overlap is required. (5) Divergent lncRNAs: These are lncRNAs that are created by the use of a promoter in the opposite direction to a protein encoding gene. (6) lncRNAs that host for micro RNAs or snoRNAs: when said small RNAs are on the same strand as an lncRNA [104].

An increasing number of studies have reported that lncRNAs have important functions in regulating various cellular processes, such as transcription, post-transcriptional modifications, post-transcriptional mRNA regulation, and regulation of the cytoskeleton organization. Some of these functions are schematized in Figure-3. IncRNAs can act as guide molecules for chromatin-modifying protein complexes to regulate epigenetic control of gene expression [105] (Figure 3-A). The actively transcribed enhancer element can lead to enhancer RNA (eRNA) production or enhancer-associated RNAs. eRNAs can capture transcription factors and several enhancerassociated lncRNAs have been shown to activate transcription as cis and trans [106] (Figure 3-B). The lncRNA can suppress transcription by detaching the transcription pre-initiation complex in the main promoter of the gene to be transcribed [107] (Figure 3-C). LncRNA can bind to target mRNAs, resulting in increased stability of mRNAs [108] (Figure 3-D). IncRNAs can target mRNAs for degradation in a process called staufen 1 (STAU1) mediated degradation [109] (Figure 3-E). LncRNAs are concerned with the creation and maintenance of nuclear structures and the coordination of nuclear architecture among various chromosomes. Paraspeckles are nuclear structures that play a role in the further regulation of adenosine, are known to contain lncRNA NEAT1 and are believed to contribute to

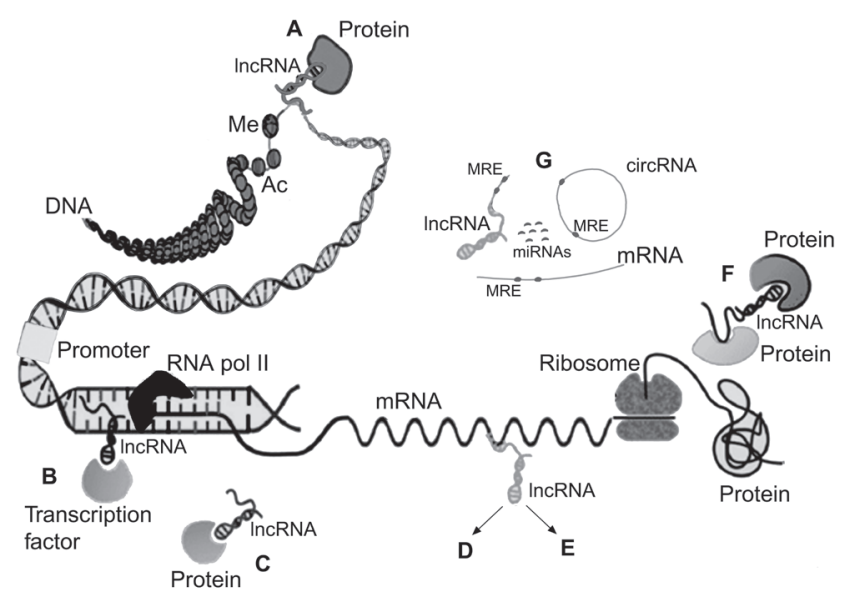

Figure 3. Functions of IncRNAs (Abbreviations: Me: Methyl, Ac: Acetyl).

the nuclear retention of mRNAs [110] (Figure 3-F). Some of the lncRNAs act as "competitive endogenous RNA (ceRNA)" by removing circRNA and miRNAs from mRNA targets. The ceRNA mechanism works as follows: miRNAs are widely accepted as active negative regulators of gene expression and reduce the stability or limit translation of the target mRNA. The miRNA is complementary to the miRNA response element (MRE) of the target mRNA called the core region (usually 6-8 nucleotides in length) in the 3 'UTR and acts by binding there. However, miRNA does not only interact with mRNA, but other endogenous RNAs, such as lncRNA and circRNA with MRE sequence, can compete with mRNA for the same miRNA pool. Several lncRNAs act as rival endogenous RNAs, also called "miRNA sponges", fine-tuning the regulation of gene expression by coupling with miRNAs. These lncRNAs contain multiple binding sites for one or more miRNAs and titrate the miRNA away from the true mRNA targets. Thus, it modifies target mRNA expression by modulating miRNA-mediated posttranscriptional silencing [111] (Figure 3-G).

Genomic imprinting and $\mathrm{X}$ chromosome inactivation studies are the first studies to define roles for two lncRNA H19 RNA and Xist RNA, respectively, and reveal a role for lncRNAs in epigenetic regulation. H19 lncRNA is spliced, polyadenylated, transported to the cytoplasm and plays a role in genomic imprinting by achieving high cytosolic concentration. Even though it is the first gene closely associated with genomic imprinting, the function of $\mathrm{H} 19$ is still unclear. It has recently been found that H19 lncRNA contains a miR-625 precursor in human and rat cells [112]. This indicates that H19 lncRNA regulates gene expression through a miRNA based mechanism. The 17 kilobase long Xist lncRNA is essential for inactivation of the $\mathrm{X}$ chromosome. Xist lncRNA does not go to cytoplasm; instead, the cis effectively silences genes by covering the surface of the $\mathrm{X}$ chromosome to be inactivated [113]. Another mechanism for $\mathrm{X}$ chromosome inactivation Xist and Tsix lncRNAs can form an RNA dimmer that is processed by the dicer enzyme to form siRNAs. These different approaches can coordinate the roles of lncRNAs and small RNAs in chromatin remodeling, which indicates that there is a more complex and interactive regulatory network by the regulator ncRNAs [114].

Studies have shown that dysregulations in IncRNA profiles are associated with the regulation of cell proliferation, differentiation, apoptosis, cell cycle, migration, invasion, epithelial-mesenchymal transition (EMT) and antitumor drug resistance in relation to the pathogenesis of cancer [115-117]. 
Chemoresistance, including intrinsic and acquired anticancer drug resistance, remains the primary barrier to curative cancer treatment. Therefore, deciphering the underlying molecular mechanisms is very important to overcome chemoresistance. Cumulative evidence has shown that lncRNAs play an important role in maintaining anticancer drug resistance across a wide range of cancer. Therefore, many lncRNAs are candidates to be new therapeutic targets in the treatment of malignancies by revealing their critical functions in chemoresistance [118]. In addition to neurodegenerative diseases, there is growing evidence of the importance of lncRNAs in brain development function maintenance and differentiation of neurons [119]. An increasing number of studies have found that lncRNAs are expressed in different ways and affect immune cells in various autoimmune diseases, including rheumatoid arthritis [120].

\section{circRNA}

circRNAs are formed by transforming exons, introns or both in pre-mRNA into circular RNA with the "back-splicing" mechanism, which is an atypical splicing mechanism. During this process, the transcripts that will form the circRNA are connected to each other by their phosphodiester bond with 3 'and 5 ' ends and a circular RNA molecule is formed [121]. Thus, circRNAs do not have 5 'cap and 3' tail regions, making them resistant to digestion of ribonuclease such as RNase $\mathrm{R}$, and provides a long half-life up to 10 times that of linear RNAs [122].

The first circRNA molecule was found in an RNA virus in 1976 [123]. In 1991, circRNAs were observed in eukaryotic cell lines by electron microscopy [124]. Then circRNAs were considered as abnormal splicing products for a long time [125]. Thanks to the genomic and transcriptomic data produced by the new generation sequencing technology and bioinformatics algorithms, a significant amount of circRNA was identified in eukaryotes and it was shown that they were not coincidental byproducts or abnormal "splicing residues" [126].

There are three different types of circRNAs, depending on the sequence contents: (1) exonic circRNAs (ecRNA), (2) intronic circRNAs (ciRNA), and (3) exon-intron circRNA (eicRNA) [127]. It has been shown that some intron containing circRNAs are sequestered in the nucleus and exonic circRNAs are transferred to the cytoplasm. Most of the circRNAs currently discovered are exonic and commonly found in the cytoplasm [128]. Although various classifications are made in different sources, there is no valid standard system for naming circRNAs. There are many circRNAs listed in public databases such as CIRCpedia, circBank and circBase, which currently use different identifiers [129-131].

circRNA is an evolutionarily conserved RNA class. They are abundant in the cell and are widely expressed in tissues. Recent studies have shown that there are about 15000 human circRNA sequences in mouse or rat genomes [132]. It has been shown that a large number of circRNAs are expressed in mammalian cells, fungi, plants and protists [133]. circRNAs are expressed in the vast majority of human tissues and are highly found in the brain, in particular [134]. Also, the expression of circRNAs always has tissue or cell specificity. This makes them a suitable candidate for biomarker studies in human cancers [135].

High-output technologies such as the ribosome RNAdepleted RNA-seq method and, more importantly, advances in preparing bioinformatics algorithms for circRNAs, enable the identification of circRNAs and their potential functions in depth. In a study using the rRNA-depleted RNA-seq method, mixed exons and potential circRNAs in human cancers were detected [136]. In a study that systematically investigated circRNAs in mice and nematodes, it was found that circRNAs were expressed in a manner specific to tissue and developmental stage [137]. In some studies, a genome-wide RNA exonuclease enrichment strategy was applied before sequencing for further circRNA identification. This method led to the enrichment of the sample in terms of circRNAs, thereby defining much more circRNAs [138]. In a recent study, the circRNAs in more than 2000 cancer samples were detected and characterized using the exome capture RNA-seq method [139].

circRNA can combine with miRNAs and function as a miRNA sponge that can isolate them from natural mRNA targets [140]. The data obtained shows that ecRNA plays a role mainly in cytoplasm in various pathological and physiological processes through the ceRNA mechanism [141] (Figure 3G). In a study, circRNAs were reported to be effective in the regulation of autoimmunity and inflammation through the ceRNA mechanism [142]. The best known example for the competitive endogenous RNA mechanism is ciRS-7, which contains more than seventy conserved binding sites for miR-7. On the other hand, ciRNA and eicRNAs usually regulate targeted genes in the nucleus $[143,144]$.

Another important function of circRNAs is to act as a protein sponge. In this mechanism, a molecular reservoir of proteins is created by binding specific proteins to circRNAs. Thus, it is possible to create a rapid response to extracellular stimuli [145].

circRNAs act as miRNA sponges and miRNA reservoirs, playing a role in regulating various immune disorders through epigenetic modifications [146]. Accumulating data reveal the vital roles of circRNAs in various diseases such as cancer, neurological disorders and cardiovascular diseases [147]. The critical role of circRNAs in antiviral immunity is well documented, which provides potential therapeutic strategies for antiviral treatments to target circRNAs [148].

Although circRNAs are considered non-coding elements, some studies have shown hidden peptides encoded by circRNAs, which will greatly expand our understanding of the physiological functions in the cell [149]. Based on our traditional views, 5 'and 3' UTRs are essential elements for initiating translation in eukaryotic cells. Although circRNAs are considered non-coding RNAs due to the absence of 5 'and 3' inserts, recent evidence suggests that circRNAs can be associated with polysomes, and some contain the start codon AUG and an open reading frame (ORF). According to these results, circRNAs can encode some regulator peptides and a hidden proteome encoded by circRNAs can be found [150]. Indeed, studies on this subject support this view. The SNF2 histone-binding PHD RING helicase (SHPRH)" gene, a circRNA gene, encodes the 146 amino acid SHPRH protein and is abundantly expressed in the normal human brain. Overexpression of SHPRH protein has been shown to reduce malignant behavior and tumor formation in glioblastoma in vitro and in vivo [151]. In another study, an 87-amino acid peptide encoded by the circRNA gene, LINC-PINT (long intergenic nonprotein-coding RNA p53-induced transcript) gene, was shown to suppress the proliferation of glioblastoma cells in vitro and in vivo [152]. 


\section{Future perspectives}

Recent discoveries of short and long regulator ncRNAs in recent years have demonstrated the importance and also complexity of RNA-mediated regulation in almost all biological processes. In this case, an average gene locus is much more complex than previously thought. Adding short and long regulator ncRNAs to our knowledge of alternative splicing and multiple transcription initiation and termination sites overly complicates the composition and regulation of gene loci. These new developments in the field of regulator ncRNA biology clearly show that some previous dogmas about genetics and epigenetics should be reorganized, taking into account the increasing complexity of RNA species and gene loci.

Initially, miRNA, siRNA, piRNA, IncRNA and circRNA were thought to function independently, and this assumption was strengthened due to the obvious differences between them. However, it has become increasingly difficult to see the functions of each of the regulator ncRNAs isolated from the others. Because all these regulator ncRNAs target the mRNA of many other genes, the mRNA of each gene can be targeted by multiple regulator ncRNAs, and therefore the regulator ncRNAs link related genes to the regulator networks. Recent studies have revealed that some of the regulator ncRNAs encode protein, and even circRNAs can encode a hidden proteome, suggesting that functions related to regulator ncRNAs may be more complex than predicted.

At the moment, the first thing to do is to understand the mechanism of action of the regulator ncRNAs and their relationships. For this purpose, we need to systematically find each of the regulator ncRNAs and analyze the relationships between them. This can require new methods in gene and genome screening technologies. The ultimate aim is to clarify the detailed regulation mechanisms of regulator ncRNAs and their interactions with normal cell biology and pathology.

Disclosures: There is no conflict of interest for all authors. Acknowledgements: Thank you to Health Sciences University Gülhane Medical Faculty.

Funding: No financial support was received for the writing of the article.

\section{References}

1. Schleiden MJ. "Beiträge zur Phytogenesis". Archiv für Anatomie, Physiologie und wissenschaftliche Medicin. 1838; $137-176$.

2. Schwann T. Mikroskopische Untersuchungen über die Uebereinstimmung in der Struktur und dem Wachsthum der Thiere und Pflanzen. Sander. 1839; 1. Auflage.

3. Crick F. Central dogma of molecular biology. Nature. 1970; 227:561-563. https://doi.org/10.1038/227561a0

4. Seal RL, Chen L, Griffiths-Jones S, Lowe TM, Mathews MB, O'Reilly D, et al. A guide to naming human non-coding RNA genes. The EMBO Journal. 2020; e103777. https://doi.org/10.15252/embj.2019103777

5. Andersen J, Delihas N, Ikenaka K, Green PJ, Pines O, Ilercil O, et al. The isolation and characterization of RNA coded by the micF gene in Escherichia coli. Nucleic Acids Res. 1987; 15:2089-2101. https://doi.org/10.1093/nar/15.5.2089

6. Lee RC, Feinbaum RL, Ambros V. The C. elegans heterochronic gene lin-4 encodes small RNAs with antisense complementarity to lin-14. Cell. 1993; 75:843-854. https://doi.org/10.1016/0092-8674(93)90529-Y

7. Brannan CI, Dees EC, Ingram RS, Tilghman SM. The product of the H19 gene may function as an RNA. Mol Cell Biol. 1990; 10:2836. https://doi.org/10.1128/MCB.10.1.28

8. Brockdorff N, Ashworth A, Kay GF, McCabe VM, Norris DP, Cooper PJ, et al. The product of the mouse Xist gene is a $15 \mathrm{~kb}$ inactive X-specific transcript containing no conserved ORF and located in the nucleus. Cell. 1992; 71:515-526. https://doi.org/10.1016/00928674(92)90519-I

9. Fire A, Xu S, Montgomery MK, Kostas SA, Driver SE, Mello CC. Potent and specific genetic interference by double-stranded RNA in Caenorhabditis elegans. Nature. 1998; 391:806-11. https://doi.org/10.1038/35888

10. Pasquinelli AE, Reinhart BJ, Slack F, Martindale MQ, Kuroda MI, Maller B, et al. Conservation of the sequence and temporal expression of let-7 heterochronic regulatory RNA. Nature. 2000; 408:86-89. https://doi.org/10.1038/35040556

11. Reinhart BJ, Slack FJ, Basson M, Pasquinelli AE, Bettinger JC, Rougvie AE, et al. The 21-nucleotide let-7 RNA regulates developmental timing in Caenorhabditis elegans. Nature. 2000; 403:901-906. https://doi.org/10.1038/35002607

12. Calin GA, Dumitru CD, Shimizu M, Bichi R, Zupo S, Noch E, et al. Frequent deletions and down-regulation of micro-RNA genes miR15 and miR16 at 13q14 in chronic lymphocytic leukemia. Proc Natl Acad Sci USA. 2002; 99:15524-15529. https://doi.org/10.1073/ pnas. 242606799

13. Eis PS, Tam W, Sun L, Chadburn A, Li Z, Gomez MF, et al. Accumulation of miR-155 and BIC RNA in human B cell lymphomas. Proc Natl Acad Sci USA. 2005; 102:3627-3632. https://doi.org/10.1073/pnas.0500613102

14. He L, Thomson JM, Hemann MT, Hernando-Monge E, Mu D, Goodson S, et al. A microRNA polycistron as a potential human oncogene. Nature. 2005; 435:828-833. https://doi.org/10.1038/nature03552

15. Venter JC, Adams MD, Myers EW, Li PW, Mural RJ, Sutton GG, et al. The Sequence of the Human Genome. Science. 2001; 291:13041351. https://doi.org/10.1126/science. 1058040

16. The ENCODE Project Consortium. An Integrated Encyclopedia of DNA Elements in the Human Genome. Nature. 2012; 489:57-73. https://doi.org/10.1038/nature11247

17. Anastasiadou E, Jacob LS and Slack FJ. Non-coding RNA networks in cancer. Nature. 2018; 18:5-18. https://doi.org/10.1038/nrc.2017.99

18. Huntzinger E, Izaurralde E. Gene silencing by microRNAs: contributions of translational repression and mRNA decay. Nat Rev Genet. 2011; 12:99-110. https://doi.org/10.1038/nrg2936

19. Lagos-Quintana M, Rauhut R, Lendeckel W, Tuschl T. Identification of novel genes coding for small expressed RNAs. Science. 2001; 294:853-858. https://doi.org/10.1126/science.1064921

20. Lau NC, Lim LP, Weinstein EG, Bartel DP. An abundant class of tiny RNAs with probable regulatory roles in Caenorhabditis elegans. Science. 2001; 294:858-862. https://doi.org/10.1126/science.1065062

21. Ambros V, Bartel B, Bartel DP, Burge CB, Carrington JC, Chen X, et al. A uniform system for microRNA annotation. RNA. 2003; 9:277-279. https://doi.org/10.1261/rna.2183803 
22. Griffiths-Jones S. The microRNA registry. Nucleic Acids Res. 2004; 32:D109-D111. https://doi.org/10.1093/nar/gkh023

23. Kozomara A, Birgaoanu M, Griffiths-Jones S. miRBase: from microRNA sequences to function. Nucleic Acids Res. 2019; 47:D155-D162. https://doi.org/10.1093/nar/gky1141

24. Lee Y, Kim M, Han J, Yeom K, Lee S, Baek SH, et al. MicroRNA genes are transcribed by RNA polymerase II. EMBO J. 2004; 23:4051-4060. https://doi.org/10.1038/sj.emboj.7600385

25. Chu CY, Rana TM. Small RNAs: regulators and guardians of the genome. J Cell Physiol. 2007; 213:412-419. https://doi.org/10.1002/ jcp. 21230

26. Bartel DP. MicroRNAs: target recognition and regulatory functions. Cell. 2009; 136:215-233. https://doi.org/10.1016/j.cell.2009.01.002

27. Huang T, Alvarez A, Hu B, Cheng S-Y. Noncoding RNAs in cancer and cancer stem cells. Chin J Cancer. 2013b; 32:582. https://doi. org/10.5732/cjc.013.10170

28. Majidinia M, Yousefi B. DNA damage response regulation by microRNAs as a therapeutic target in cancer. DNA Repair. 2016; 47:1-11. https://doi.org/10.1016/j.dnarep.2016.09.003

29. Lee Y, Ahn C, Han J, Choi H, Kim J, Yim J, et al. The nuclear RNase III Drosha initiates microRNA processing. Nature. 2003; 425:415419. https://doi.org/10.1038/nature01957

30. Denli AM, Tops BB, Plasterk RH, Ketting RF, Hannon GJ. Processing of primary microRNAs by the Microprocessor complex. Nature. 2004; 432:231-235. https://doi.org/10.1038/nature03049

31. Terry LJ, Shows EB, Wente SR. Crossing the nuclear envelope: hierarchical regulation of nucleocytoplasmic transport. Science. 2007; 318:1412-1416. https://doi.org/10.1126/science.1142204

32. 32. Bohnsack MT, Czaplinski K, Go rlich D. Exportin 5 is a RanGTP-dependent dsRNA-binding protein that mediates nuclear export of pre-miRNAs. RNA. 2004; 10:185-191. https://doi.org/10.1261/rna.5167604

33. Chendrimada, TP, Gregory RI, Kumaraswamy E, Norman J, Cooch N, Nishikura K, et al. TRBP recruits the Dicer complex to Ago 2 for microRNA processing and gene silencing. Nature. 2005; 436:740-744. https://doi.org/10.1038/nature03868

34. Bartel DP. MicroRNAs: genomics, biogenesis, mechanism, and function. Cell. 2004;116:281-297. https://doi.org/10.1016/S00928674(04)00045-5

35. Bartel DP. MicroRNAs: target recognition and regulatory functions. Cell. 2009; 136:215-233. https://doi.org/10.1016/j.cell.2009.01.002

36. Filipowicz W, Bhattacharyya SN, Sonenberg N. Mechanisms of post-transcriptional regulation by microRNAs: are the answers in sight? Nat Rev Genet. 2008; 9:102-114. https://doi.org/10.1038/nrg2290

37. Du P, Wang L, Sliz P, Gregory RI. A biogenesis step upstream of microprocessor controls miR-17 92 expression. Cell. 2015; 162:88599. https://doi.org/10.1016/j.cell.2015.07.008

38. Kim YK, Kim VN. Processing of intronic microRNAs. EMBO J. 2007; 26:775-783. https://doi.org/10.1038/sj.emboj.7601512

39. Rodriguez A, Griffiths-Jones S, Ashurst JL, Bradley A. Identification of mammalian microRNA host genes and transcription units. Genome Res. 2004; 14:1902-1910. https://doi.org/10.1101/gr.2722704

40. Ghorai A, Ghosh U. miRNA gene counts in chromosomes vary widely in a species and biogenesis of miRNA largely depends on transcription or post-transcriptional processing f coding genes. Front Genet. 2014; 5:100. https://doi.org/10.3389/fgene.2014.00100

41. Bartel DP. Metazoan MicroRNAs. Cell. 2018; 173: 20-51 https://doi.org/10.1016/j.cell.2018.03.006

42. Friedman RC, Farh KK-H, Burge CB, Bartel DP. Most mammalian mRNAs are conserved targets of microRNAs. Genome Res. 2009; 19:92-105. https://doi.org/10.1101/gr.082701.108

43. Friedman RC, Farh KK, Burge CB, Bartel DP. Most mammalian mRNAs are conserved targets of microRNAs. Genome Res. 2009; 19:92-105. https://doi.org/10.1101/gr.082701.108

44. Sayed D, Abdellatif M. MicroRNAs in development and disease. Physiol Rev. 2011; 91:827-87. https://doi.org/10.1152/ physrev.00006.2010

45. Esteller M. Non-coding RNAs in human disease. Nat Rev Genet. 2011; 12:861-74. https://doi.org/10.1038/nrg3074

46. Liu N, Olson EN. MicroRNA regulatory networks in cardiovascular development. Dev Cell. 2010; 18:510-25. https://doi.org/10.1016/j. devcel.2010.03.010

47. Issler O, Chen A. Determining the role of microRNAs in psychiatric disorders. Nat Rev Neurosci. 2015; 16:201-12. https://doi. org/10.1038/nrn3879

48. Mencía A, Modamio-Høybjør S, Redshaw N, Morín M, Mayo-Merino F, Olavarrieta L, et al. Mutations in the seed region of human miR-96 are responsible for nonsyndromic progressive hearing loss. Nat Genet. 2009; 41:609-613. https://doi.org/10.1038/ng.355

49. Panagal M, Biruntha M, Vidhyavathi RM, Sivagurunathan P, Senthilkumar SR, Sekar D. Dissecting the role of miR-21 in different types of stroke. Gene. 2019; 681:69-72. https://doi.org/10.1016/j.gene.2018.09.048

50. Yan JJ, Qiao M, Li RH, Zhao XT, Wang XY, Sun Q. Downregulation of miR-145-5p contributes to hyperproliferation of keratinocytes and skin inflammation in psoriasis. Br J Dermatol. 2019; 180:365-372. https://doi.org/10.1111/bjd.17256

51. Fernández-Ramos D, Fernández-Tussy P, Lopitz-Otsoa F, Gutiérrez-de-Juan V, Navasa N, Barbier-Torres L, et al. MiR-873-5p acts as an epigenetic regulator in early stages of liver fibrosis and cirrhosis. Cell Death Dis. 2018; 9:958. https://doi.org/10.1038/s41419-0181014-y

52. Guggino G, Orlando V, Saieva L, Ruscitti P, Cipriani P, La Manna MP, et al. Downregulation of miRNA17-92 cluster marks Vc9Vd2 T cells from patients with rheumatoid arthritis. Arthritis Res Ther. 2018; 20:236. https://doi.org/10.1186/s13075-018-1740-7

53. Kwok GT, Zhao JT, Weiss J, Mugridge N, Brahmbhatt H, MacDiarmid JA, et al. Translational applications of microRNAs in cancer, and therapeutic implications. Noncoding RNA Res. 2017; 2:143-150. https://doi.org/10.1016/j.ncrna.2017.12.002

54. Weber JA, Baxter DH, Zhang S, Huang DY, Huang KH, Lee MJ, et al. The microRNA spectrum in 12 body fluids. Clin Chem. 2010; 56:1733-1741. https://doi.org/10.1373/clinchem.2010.147405

55. Wang Y, Zheng F, Gao G, Yan S, Zhang L,Wang L, et al. MiR-548a-3p regulates inflammatory response via TLR4/NF-_B signaling pathway in rheumatoid arthritis. J Cell Biochem. 2018; 120:1133-40. https://doi.org/10.1002/jcb.26659

56. Keller S, Sanderson MP, Stoeck A, Altevogt P. Exosomes: from biogenesis and secretion to biological function. Immunol Lett. 2006; 107:102-8. https://doi.org/10.1016/j.imlet.2006.09.005 
57. Xu D, Song M, Chai C, Wang J, Jin C, Wang X, et al. Exosome-encapsulated miR-6089 regulates inflammatory response via targeting TLR4. J Cell Physiol. 2019; 234:1502-11. https://doi.org/10.1002/jcp.27014

58. Costinean S, Zanesi N, Pekarsky Y, Tili E, Volinia S, Heerema N, et al. Pre-B cell proliferation and lymphoblastic leukemia/ high-grade lymphoma in E(mu)-miR155 transgenic mice. Proc Natl Acad Sci USA. 2006; 103:7024-7029. https://doi.org/10.1073/pnas.0602266103

59. Acunzo M, Romano G, Wernicke D, Croce CM. MicroRNA and cancer-a brief overview. Adv Biol Regul. 2015; 57:1-9. https://doi. org/10.1016/j.jbior.2014.09.013

60. Iorio MV, Croce CM. microRNA involvement in human cancer. Carcinogenesis. 2012; 33:1126-1133. https://doi.org/10.1093/carcin/ bgs 140

61. Moazed D. Small RNAs in transcriptional gene silencing and genome defence. Nature. 2009; 457:413-420. https://doi.org/10.1038/ nature 07756

62. Kim VN, Han J, Siomi MC. Biogenesis of small RNAs in animals. Nat Rev Mol Cell Biol. 2009; 10:126-39. https://doi.org/10.1038/ nrm 2632

63. Siomi H, Siomi MC. On the road to reading the RNA-interference code. Nature. 2009; 457:396-404. https://doi.org/10.1038/nature07754

64. Hombach S, Kretz M. Non-coding RNAs: Classification, Biology and Functioning. Adv Exp Med Biol. https://doi.org/10.1007/978-3319-42059-2_1

65. Nayak A, Tassetto M, Kunitomi M, Andino R. RNA interference-mediated intrinsic antiviral immunity in invertebrates. Intrinsic Immun. 2013; In: Cullen BR, editör:183-200. https://doi.org/10.1007/978-3-642-37765-5_7

66. García-Sastre A. Induction and evasion of type I interferon responses by infl uenza viruses. Virus Res. 2011; 162:12-8. https://doi. org/10.1016/j.virusres.2011.10.017

67. Sleutels F, Zwart R, Barlow D. The non-coding Air RNA is required for silencing autosomal imprinted genes. Nature. 2002; 415:810-3. https://doi.org/10.1038/415810a

68. Mao Y, Sunwoo H, Zhang B, Spector D. Direct visualization of the co-transcriptional assembly of a nuclear body by noncoding RNAs. Nat Cell Biol. 2011; 13:95-101. https://doi.org/10.1038/ncb2140

69. Vagin VV, Sigova A, Li C, Seitz H, Gvozdev V, Zamore PD. A distinct small RNA pathway silences selfish genetic elements in the germline. Science. 2006; 313:320-24. https://doi.org/10.1126/science.1129333

70. Romano G, Veneziano D, Acunzo M, Croce CM. Small non-coding RNA and cancer. Carcinogenesis. 2017; 385-5:485-491. https:// doi.org/10.1093/carcin/bgx026

71. Kim VN. Small RNAs just got bigger: Piwi-interacting RNAs (piRNAs) in mammalian testes. Genes Dev. 2006; 20:1993-1997. https:// doi.org/10.1101/gad.1456106

72. Aravin A, Gaidatzis D, Pfeffer S, Lagos-Quintana M, Landgraf P, Iovino N, et al. A novel class of small RNAs bind to MILI protein in mouse testes. Nature. 2006; 442:203-207. https://doi.org/10.1038/nature04916

73. Girard A, Sachidanandam R, Hannon GJ, Carmell MA. A germline-specific class of small RNAs binds mammalian Piwi proteins. Nature. 2006; 442:199-202. https://doi.org/10.1038/nature04917

74. Grivna ST, Beyret E, Wang Z, Lin H. A novel class of small RNAs in mouse spermatogenic cells. Genes Dev. 2006; 20:1709-1714. https://doi.org/10.1101/gad.1434406

75. Watanabe T, Takeda A, Tsukiyama T, Mise K, Okuno T, Sasaki H, et al. Identification and characterization of two novel classes of small RNAs in the mouse germline: retrotransposonderived siRNAs in oocytes and germline small RNAs in testes. Genes Dev. 2006; 20:17321743. https://doi.org/10.1101/gad.1425706

76. Malone CD, Hannon GJ.. Small RNAs as guardians of the genome. Cell. 2009; 136:656-68. https://doi.org/10.1016/j.cell.2009.01.045

77. Iwasaki YW, Siomi MC, Siomi H. PIWI-Interacting RNA: Its Biogenesis and Functions. Annu Rev Biochem. 2015; 84:405-33. https:// doi.org/10.1146/annurev-biochem-060614-034258

78. Vagin VV, Sigova A, Li C, Seitz H, Gvozdev V, Zamore PD. A distinct small RNA pathway silences selfish genetic elements in the germline. Science. 2006; 313:320-24. https://doi.org/10.1126/science.1129333

79. Weick EM, Miska EA. piRNAs: from biogenesis to function. Development. 2014; 141:3458-3471. https://doi.org/10.1242/dev.094037

80. Wang G, Reinke V. A C. elegans Piwi, PRG-1, regulates 21U-RNAs during spermatogenesis. Curr Biol. 2008; 18(12): 861-867. https:// doi.org/10.1016/j.cub.2008.05.009

81. Thomson T, Lin H. The biogenesis and function of PIWI proteins and piRNAs: progress and prospect. Annu Rev Cell Dev Biol. 2009; 25:355-76. https://doi.org/10.1146/annurev.cellbio.24.110707.175327

82. Li C, Vagin VV, Lee S, Xu J, Ma S, Xi H, et al. Collapse of germline piRNAs in the absence of Argonaute 3 reveals somatic piRNAs in flies. Cell. 2009; 137:509-21. https://doi.org/10.1016/j.cell.2009.04.027

83. Khurana JS, Xu J, Weng Z, Theurkauf WE. Distinct functions for the Drosophila piRNA pathway in genome maintenance and telomere protection. PLOS Genet. 2010; 6:e1001246. https://doi.org/10.1371/journal.pgen.1001246

84. Aravin AA, Sachidanandam R, Girard A, Fejes-Toth K, Hannon GJ. Developmentally regulated piRNA clusters implicate MILI in transposon control. Science. 2007; 316:744-47. https://doi.org/10.1126/science.1142612

85. Aravin AA, Sachidanandam R, Bourc'his D, Schaefer C, Pezic D, Toth KF, et al. A piRNA pathway primed by individual transposons is linked to de novo DNA methylation in mice. Mol Cell. 2008; 31:785-799. https://doi.org/10.1016/j.molcel.2008.09.003

86. Yin H, Lin H. An epigenetic activation role of Piwi and a Piwi-associated piRNA in Drosophila melanogaster. Nature. 2007; 450:304308. https://doi.org/10.1038/nature06263

87. Huang XA, Yin H, Sweeney S, Raha D, Snyder M, Lin H. A major epigenetic programming mechanism guided by piRNAs. Dev Cell. 2013; 24:502-516. https://doi.org/10.1016/j.devcel.2013.01.023

88. Bourc'his D, Bestor TH. Meiotic catastrophe and retrotransposon reactivation in male germ cells lacking Dnmt3L. Nature. 2004; 431:96-99. https://doi.org/10.1038/nature02886

89. Kuramochi-Miyagawa S, Watanabe T, Gotoh K, Totoki Y, Toyoda A, Ikawa M, et al. DNA methylation of retrotransposon genes is regulated by Piwi family members MILI and MIWI2 in murine fetal testes. Genes Dev. 2008; 22:908-917. https://doi.org/10.1101/ gad. 1640708 
90. Mei Y, Wang Y, Kumari P, Shetty AC, Clark D, Gable T, et al. A piRNA-like small RNA interacts with and modulates p-ERM proteins in human somatic cells. Nat Commun. 2015; 6:7316. https://doi.org/10.1038/ncomms8316

91. Hashim A, Rizzo F, Marchese G, Ravo M, Tarallo R, Nassa G, et al. RNA sequencing identifies specific PIWIinteracting small noncoding RNA expression patterns in breast cancer. Oncotarget. 2014; 5:9901-9910. https://doi.org/10.18632/oncotarget.2476

92. Ishizu H, Siomi H, Siomi MC. Biology of PIWI-interacting RNAs: new insights into biogenesis and function inside and outside of germlines. Genes Dev. 2012; 26:2361-73. https://doi.org/10.1101/gad.203786.112

93. Bassett AR, Akhtar A, Barlow DP, Bird AP, Brockdorff N, Duboule D, et al. Considerations when investigating lncRNA function in vivo. eLife. 2014. https://doi.org/10.7554/eLife.03058

94. Kung JTY, Colognori D, Lee JT. Long noncoding RNAs: past, present, and future. Genetics. 2013; 193:651-69. https://doi.org/10.1534/ genetics. 112.146704

95. Brannan CI, Dees EC, Ingram RS, Tilghman SM. The product of the H19 gene may function as an RNA. Mol Cell Biol. 1990; 10: 2836. https://doi.org/10.1128/MCB.10.1.28

96. Tiedge H, Chen W, Brosius J. Primary structure, neural-specific expression, and dendritic location of human BC200 RNA. J Neurosci. 1993; 13:2382-2390. https://doi.org/10.1523/JNEUROSCI.13-06-02382.1993

97. Brown CJ, Ballabio A, Rupert JL, Lafreniere RG, Grompe M, Tonlorenzi R, et al. A gene from the region of the human X inactivation centre is expressed exclusively from the inactive X chromosome. Nature. 1991; 349:38-44. https://doi.org/10.1038/349038a0

98. Lander ES, Linton LM, Birren B, Nusbaum C, Zody MC, Baldwin J, et al. Initial sequencing and analysis of the human genome. Nature. 2001; 409:860-921. https://doi.org/10.1038/35057062

99. Erdmann VA, Szymanski M, Hochberg A, de Groot N, Barciszewski. Collection of mRNA-like non-coding RNAs. Nucleic Acids Res. 1999; 27:192-195. https://doi.org/10.1093/nar/27.1.192

100. Kapranov P, Cheng J, Dike S, Nix DA, Duttagupta R, Willingham AT, et al. RNA maps reveal new RNA classes and a possible function for pervasive transcription. Science. 2007; 316:1484-1488. https://doi.org/10.1126/science.1138341

101. Novikova IV, Hennelly SP, Sanbonmatsu KY. Tackling structures of long noncoding RNAs. Int J Mol Sci. 2013; 14(12):23672-23684. https://doi.org/10.3390/ijms141223672

102. Bohmdorfer G, Sethuraman S, Rowley MJ, Krzyszton M, Rothi MH, Bouzit L, et al. Long non-coding RNA produced by RNA polymerase V determines boundaries of heterochromatin. Elife. 2016; 5:e19092. https://doi.org/10.7554/eLife.19092

103. Ponting CP, Oliver PL, Reik W. Evolution and functions of long noncoding RNAs. Cell. 2009; 136:629-641. https://doi.org/10.1016/j. cell.2009.02.006

104. Crick FH. On protein synthesis. Symp Soc Exp Biol. 1958; 12:138-163.

105. Khalil A, Guttman M, Huarte M, Garber M, Raj A, Rivea Morales D, et al. Many human large intergenic noncoding RNAs associate with chromatinmodifying complexes and affect gene expression. Proc Natl Acad Sci USA. 2009; 106:11667-72. https://doi.org/10.1073/ pnas.0904715106

106. Melo CA, Drost J, Wijchers PJ, van de Werken H, de Wit E, Vrielink JAFO, et al. eRNAs are required for p53-dependent enhancer activity and gene transcription. Mol Cell. 2013; 49:524-35. https://doi.org/10.1016/j.molcel.2012.11.021

107. Martianov I, Ramadass A, Serra Barros A, Chow N, Akoulitchev A. Repression of the human dihydrofo-late reductase gene by a noncoding interfering transcript. Nature. 2007; 445:666-70.https://doi.org/10.1038/nature05519

108. Kretz M, Siprashvili Z, Chu C, Webster DE, Zehnder A, Qu K, et al. Control of somatic tissue differentiation by the long non-coding RNA TINCR. Nature. 2013; 493:231-5. https://doi.org/10.1038/nature11661

109. Gong C, Maquat L. IncRNAs transactivate STAU1- mediated mRNA decay by duplexing with 3' UTRs via Alu elements. Nature. 2011; 470:284-8. https://doi.org/10.1038/nature09701

110. Sunwoo H, Dinger ME, Wilusz JE, Amaral PP, Mattick JS, Spector DL. MEN \&// nuclear-retained non-coding RNAs are up-regulated upon muscle differentiation and are essential components of paraspeckles. Genome Res. 2009; 19:347-59. https://oi.org/10.1101/ gr.087775.108

111. Ebert M, Sharp P. Emerging roles for natural microRNA sponges. Curr Biol CB. 2010; 20:R858-61. https://doi.org/10.1016/j. cub.2010.08.052

112. Cai X, Cullen BR. The imprinted H19 noncoding RNA is a primary microRNA precursor. RNA. 2007; 13: 313-316. https://doi. org/10.1261/rna.351707

113. Clemson CM, McNeil JA, Willard HF, Lawrence JB. XIST RNA paints the inactive X chromosome at interphase: Evidence for a novel RNA involved in nuclear/chromosome structure. J Cell Biol. 1996; 132:259-275. https://doi.org/10.1083/jcb.132.3.259

114. Ogawa Y, Sun BK, Lee JT. Intersection of the RNA interference and X-inactivation pathways. Science. 2008; 320:1336-1341. https:// doi.org/10.1126/science. 1157676

115. Klec C, Prinz F, Pichler M. Involvement of the long noncoding RNA NEAT1 in carcinogenesis. Mol Oncol. 2019; 13(1):46-60. https:// doi.org/10.1002/1878-0261.12404

116. Liu X. ABC family transporters. Adv Exp Med Biol. 2019; 1141:13-100. https://doi.org/10.1007/978-981-13-7647-4_2

117. Liu Y, Yin L, Chen C, Zhang X, Wang S. Long non-coding RNA GAS5 inhibits migration and invasion in gastric cancer via interacting with p53 protein. Dig Liver Dis. 2020; 52(3):331-338. https://doi.org/10.1016/j.dld.2019.08.012

118. Jianga W, Xiab J, Xiea S, Zoua R, Pana S, Wanga Z, et al. Long non-coding RNAs as a determinant of cancer drug resistance: Towards the overcoming of chemoresistance via modulation of lncRNAs. Drug Resist Update. https://doi.org/10.1016/j.drup.2020.100683

119. Riva P, Ratti A, Venturin M. The Long Non-Coding RNAs in Neurodegenerative Diseases: Novel Mechanisms of Pathogenesis. Curr Alzheimer Res. 2016; 13:1219-1231. https://doi.org/10.2174/1567205013666160622112234

120. Liang J, Chen W, Lin J. LncRNA: An all-rounder in rheumatoid arthritis. J Transl Int Med. 2019; 7:3-9. https://doi.org/10.2478/jtim2019-0002

121. Chen LL. The biogenesis and emerging roles of circular RNAs. Nat Rev Mol Cell Biol. 2016; 17:205-211. https://doi.org/10.1038/ nrm.2015.32 
122. Memczak S, Jens M, Elefsinioti A, Torti F, Krueger J, Rybak A, et al. Circular RNAs are a large class of animal RNAs with regulatory potency. Nature. 2013; 495:333-338. https://doi.org/10.1038/nature11928

123. Kolakofsky D. Isolation and characterization of Sendai virus DI-RNAs. Cell. 1976; 8:547-55. https://doi.org/10.1016/00928674(76)90223-3

124. Hsu MT, Coca-Prados M. Electron microscopic evidence for the circular form of RNA in the cytoplasm of eukaryotic cells. Nature. 1979; 280:339-40. https://doi.org/10.1038/280339a0

125. Cocquerelle C, Mascrez B, Hetuin D, Bailleul B. Mis-splicing yields circular RNA molecules. FASEB J. 1993; 7:155-60. https://doi. org/10.1096/fasebj.7.1.7678559

126. Wang PL, Bao Y, Yee MC, Barrett SP, Hogan GJ, Olsen MN, et al. Circular RNA is expressed across the eukaryotic tree of life. PLoS One. 2014; 9:e90859. https://doi.org/10.1371/journal.pone.0090859

127. Yang L, Fu J, Zhou Y. Circular RNAs and their emerging roles in immune regulation. Front Immunol. 2018; 9:2977. https://doi. org/10.3389/fimmu.2018.02977

128. Hansen TB, Jensen TI, Clausen BH, Bramsen JB, Finsen B, Damgaard CK, et al. Natural RNA circles function as efficient microRNA sponges. Nature. 2013; 495:384-8. https://doi.org/10.1038/nature11993

129. Dong R, Ma XK, Li GW, Yang L. CIRCpedia v2: an updated database for comprehensive circular RNA annotation and expression comparison. GPB. 2018; 16: 226-233. https://doi.org/10.1016/j.gpb.2018.08.001

130. Liu M, Wang Q, Shen J, Yang BB, Ding X. Circbank: a comprehensive database for circRNA with standard nomenclature. $R N A$ Biol. 2019b; 16:899-905. https://doi.org/10.1080/15476286.2019.1600395

131. Gla zar P, Papavasileiou P, Rajewsky N. circBase: a database for circular RNAs. RNA. 2014; 20:1666-1670. https://doi.org/10.1261/ rna.043687.113

132. Dong R, Ma XK, Chen LL, Yang L. Increased complexity of circRNA expression during species evolution. RNA Biol. 2017; 14:106474. https://doi.org/10.1080/15476286.2016.1269999

133. Barrett SP, Wang PL, Salzman J. Circular RNA biogenesis can proceed through an exon-containing lariat precursor. Elife. 2015; 4:e07540. https://doi.org/10.7554/eLife.07540

134. Rybak-Wolf A, Stottmeister C, Glazar P, Jens M, Pino N, Giusti S, et al. Circular RNAs in the mammalian brain are highly abundant, conserved, and dynamically expressed. Mol Cell. 2015; 58:870-85. https://doi.org/10.1016/j.molcel.2015.03.027

135. Guo T, Ding H, Jiang H, Bao N, Zhou L, Zhao J. miR-338-5p Regulates the viability, proliferation, apoptosis and migration of rheumatoid arthritis fibroblast-like synoviocytes by targeting NFAT5. Cell Physiol Biochem. 2018; 49:899-910. https://doi.org/10.1159/000493222

136. Derks KW, Misovic B, van den Hout MC, Kockx CE, Gomez CP, Brouwer RW, et al. Deciphering the RNA landscape by RNAome sequencing. RNA Biol. 2015; 12:30-42. https://doi.org/10.1080/15476286.2015.1017202

137. Memczak S, Jens M, Elefsinioti A, Torti F, Krueger J, Rybak A, et al. Circular RNAs are a large class of animal RNAs with regulatory potency. Nature. 2013; 495:333-8.https://doi.org/10.1038/nature11928

138. Jeck WR, Sorrentino JA, Wang K, Slevin MK, Burd CE, Liu J, et al. Circular RNAs are abundant, conserved, and associated with ALUrepeats. RNA. 2013; 19:141-57. https://doi.org/10.1261/rna.035667.112

139. Vo JN, Cieslik M, Zhang Y, Shukla S, Xiao L, Wu YM, et al. The landscape of circular RNA in Cancer. Cell. 2019; 176:869-81. https:// doi.org/10.1016/j.cell.2018.12.021

140. Memczak S, Jens M, Elefsinioti A, Torti F, Krueger J, Rybak A, et al. Circular RNAs are a large class of animal RNAs with regulatory potency. Nature. 2013; 495:333-8. https://doi.org/10.1038/nature11928

141. Salmena L, Poliseno L, Tay Y, Kats L, Pandolfi PP. A ceRNA hypothesis: The Rosetta Stone of a hidden RNA language? Cell. 2011; 146:353-358. https://doi.org/10.1016/j.cell.2011.07.014

142. Zhong Y, Du Y, Yang X, Mo Y, Fan C, Xiong F, et al. Circular RNAs function as ceRNAs to regulate and control human cancer progression. Mol Cancer. 2018; 17:79. https://doi.org/10.1186/s12943-018-0827-8

143. Zheng XB, Zhang M, Xu MQ. Detection and characterization of ciRS-7: a potential promoter of the development of cancer. Neoplasma. 2017; 64:321-8. https://doi.org/10.4149/neo_2017_301

144. Zhang Y, Zhang XO, Chen T, Xiang JF, Yin QF, Xing YH, et al. Circular intronic long noncoding RNAs. Mol Cell. 2013; $51: 792-806$. https://doi.org/10.1016/j.molcel.2013.08.017

145. Abdelmohsen K, Panda AC, Munk R, Grammatikakis I, Dudekula DB, De S, et al. Identification of HuR target circular RNAs uncovers suppression of PABPN1 translation by CircPABPN1. RNA Biol. 2017; 14:361-9. https://doi.org/10.1080/15476286.2017.1279788

146. 146. Chen X, Yang T, Wang W, Xi W, Zhang T, Li Q, et al. Circular RNAs in immune responses and immune diseases. Theranostics. 2019; 9:588-607. https://doi.org/10.7150/thno.29678

147. Sheng JQ, Liu L, Wang MR, Li PY. Circular RNAs in digestive system cancer: potential biomarkers and therapeutic targets. Am J Cancer Res. 2018; 8:1142-56.

148. Wang M, Yu F, Wu W, Zhang Y, Chang W, Ponnusamy M, et al. Circular RNAs: a novel type of non-coding RNA and their potential implications in antiviral immunity. Int J Biol Sci. 2017; 13:1497-506.https://doi.org/10.7150/ijbs.22531

149. Granados-Riveron JT, Aquino-Jarquin G. The complexity of the translation ability of circRNAs. Biochim Biophys Acta. 2016; 1859:1245-51. https://doi.org/10.1016/j.bbagrm.2016.07.009

150. Abe N, Matsumoto K, Nishihara M, Nakano Y, Shibata A, Maruyama H, et al. Rolling circle translation of circular RNA in living human cells. Sci Rep. 2015; 5:16435. https://doi.org/10.1038/srep16435

151. Zhang M, Huang N, Yang X, Luo J, Yan S, Xiao F, et al. A novel protein encoded by the circular form of the SHPRH gene suppresses glioma tumorigenesis. Oncogene. 2018; 37:1805-14. https://doi.org/10.1038/s41388-017-0019-9

152. Zhang M, Zhao K, Xu X, Yang Y, Yan S, Wei P, et al. A peptide encoded by circular form of LINC-PINT suppresses oncogenic transcriptional elongation in glioblastoma. Nat Commun. 2018; 9:4475. https://doi.org/10.1038/s41467-018-06862-2 